\title{
RESULTS OF THE FLORISTIC RESEARCHES OF THE SVIYAGA RIVER WITHIN THE FRAMEWORK OF THE RGS PROJECT «THE RIVERS OF THE ULYANOVSK REGION»
}

D.A. Frolov, Candidate of biology sciences, associate professor of the department of botanic Ulyanovsk State Teacher-training University, Ulyanovsk (Russia)

Annotation. From 23d of May till 1st of June the third rafting expedition has taken place within the framework of the project «The rivers of Ulyanovsk region». It was within the framework of the project «Complex of ecological examination of the middle course of the Sviyaga river» of Ulyanovsk Russian Geographical society department. The project «The rivers of Ulyanovsk region» was rated at 4 years and now it's realizing with Ulyanovsk state department of the Russian geographical society and Simbirsk Bird protection Union department, Ulyanovsk state regional museum of I.A. Goncharov, Research center «Поволжье», Ulyanovsk state pedagogical university of I. N. Ulyanov and Ulyanovsk state university. The general aim of the scientific researches is complex ecological description of big and medium rivers of Ulyanovsk region and the assessment their modern ecological, chemical shape and biotic variety.In 2014 the researches were arranged on the Sviyags river, it was botany, entomology, ichthyology, ornithology, theriology and hydrology, also landscape description of water meadow and Sviyaga valley was made. The description of the anthropogenic load dynamics of the river was also made. There are results of the floristic researches of the Sviyaga river and geobotanical and floristic description of the examinee with the description of the most rare vegetable subjects in the article.

Keywords:flora; phytocenosis; Sviyaga river; the expedition; rare plants; protected plants; alloy; biological diversity; natural monument; the river basin.

\section{УДК 581.9 АНАЛИЗ АДВЕНТИВНОЙ ФЛОРЫ СТАНЦИИ ДЕМА (БАШКИРСКОЕ ОТДЕЛЕНИЕ КУЙБЫШЕВСКОЙ ЖЕЛЕЗНОЙ ДОРОГИ)}

C) 2015

С.А. Хусаинова, аспирант лаборатории дикорастущей флоры и интродукции травянистых растений Ботанический сад-институт УНЦ РАН, Уфа (Россия)

Э.С. Сейдалиева, студент естественно-географического факультета Башкирский государственный педагогический университет им. М.Акмулль,, Уфа (Россия) А.Ф. Хусаинов, кандидат биологических наук, доцент кафедры биоэкологи и биологического образования

Баикирский государственный педагогический университет им. М.Акмулль, Уфа (Россия)

Л.М. Абрамова, доктор биологических наук, профессор, зав. лабораторией дикорастущей флоры и интродукции травянистых растений

Ботанический сад-институт УНЦРАН, Уфа (Россия)

Аннотация. В статье рассматривается флора железнодорожных насыпей станции Дема, относящейся к Куйбышевской железной дороге. Железнодорожныенасыпиявляютсяпутями активных трансзональных иммиграций чужеродных видов растений. На данных типах ландшафтов формируются антропогенно трансформированные флористические комплексы, в сложении которых участвует большое число адвентивных видов растений.

Исследованная в 2013-2014 гг. флора насыпей станции Дема включает 217 видов, из которых 84 адвентивных видов. Среднее число видов в семействе равно 5,9. Десять ведущих семейств флоры железнодорожных путей станции - Asteraceae, Poaceae, Fabaceae, Brassicaceae, Chenopodiaceae, Lamiaceae, Rosaceae, Caryophyllaceae, Polygonaceae, Scrophulariaceae. Наиболее крупные роды - Artemisia (6 видов), Rumex (5 видов), Роа (5 видов), Centaurea (4 вида).

Проведен анализ адвентивной флоры по следующим признакам: времени и способу заноса, степени натурализации и флорогенетическому спектру. Участие заносных видов во флоре составляет $38,6 \%$, что определяет и степень ее адвентизации. Среди адвентивных видов достаточно высока роль неофитов $(25,3 \%)$. Во флоре исследуемой территории зарегистрированы новые для Республики Башкортостан виды и местообитания Ambrosia trifida, Cyclachaena xanthiifolia, Oenothera oakesiana, Oenothera biennis, Phalacroloma strigosum, Senecio viscosus, Eragrostis minor, Eragrostis pilosa.

Ключевые слова: флора; железнодорожные пути; апофиты; адвентивные виды; синантропизация.

Под влиянием антропогенных факторов, с одной стороны, происходит внедрение адвентивных видов во флоры регионов, а с другой - вымирание части аборигенных видов, что, в свою очередь, вызывает унификацию флор целых ландшафтов, маскирует и обедняет их специфичность [1, с. 5]. Особый интерес в этом отношении вызывает флора техногенных биотопов, не имеющих природных аналогов. В первую очередь, это относится к железнодорожным насыпям. На данных типах ландшафтов формируются антропогенно трансформированные флористические комплексы, в сложении которых участвует большое число адвентивных видов растений.

Влияние железнодорожного транспорта на растительный покров является актуальной проблемой, так как они служат путями активных трансзональных иммиграций адвентивных видов растений [2]. Растения, попавшие в новые районы, сначала распределяются по нарушенным местообитаниям, откуда расселяются в синантропизированные и естественные. Для установления закономерности процесса становления Самарский научный вестник. 2015. № 2(11) и развития региональных флор необходимо детальное изучение флоры железнодорожных насыпей с установлением происхождения каждого вида.

Флористические исследования железных дорог проводили многие отечественные ученые, преимущественно в европейской части России [3-10]. На Урале железные дороги почти не изучены [11].

С 2009 года нами проводится изучение флор железнодорожных насыпей Куйбышевской железной дороги в пределах Республики Башкортостан [12, 13].

Целью настоящих исследований было выявление и анализ флоры насыпей железных дорог в пределах одной из крупных сортировочных станции Куйбышевской железной дороги - станции Дема.

Природные условия района исследований

Станция Дёма является крупным комплексом, работающим на пять направлений: на Кандры, Раевку, Стерлитамак, Инзер, Кропачево и на станции Уфимского железнодорожного узла [14].

Территория района относится к Левобережному Прибельскому физико-географическому округу, 
характеризующемуся наличием обширных низменных террасовых и пологоувалистых денудационных равнин. Местами она имеет холмисто-увалистый рельеф и расчленена оврагами и балками [15].

Климат округа в целом отличается континентальностью и умеренным увлажнением. Средняя годовая температура составляет $2,8^{\circ} \mathrm{C}$. Среднее годовое количество осадков достигает 400-500 мм, из них более половины выпадает в теплую часть года [15].

Для территории округа характерны лесостепные почвы, среди которых преобладают серые и темно-серые лесные почвы и выщелоченные черноземы. Территория округа характеризуется наличием обширных степных пространств, ныне распаханных, и отдельных лесных массивов [3, с. 87].

Методика исследования

Сбор материала проводился традиционным маршрутным методом в полевые сезоны в 2013-14 гг. Обследовалось железнодорожное полотно в границах балластной призмы в межрельсовом пространстве, на обочинах путей и на территориях железнодорожных станции Дема, основным покрытием которых является щебнистая насыпь с деревянными и железобетонными шпалами. Было выполнено 20 геоботанических описаний и собрано 300 листов гербарного материала.

Идентификация растений проводилась по следующим определителям: «Определитель высших растений Башкирской АССР» под редакцией Е.В. Кучерова [16]. Список видов сосудистых растений анализировался по общепринятым методикам [17, 18]. Для анализа адвентивной фракции использовалась классификация, изложенная в работе В.В. Туганаева и А.Н. Пузырева [19]. Номенклатура видов приводится по сводкам С.К. Черепанова [20] с дополнениями О.Г. Барановой, А.Н. Пузырева [21], П.В. Куликова [2].

Результаты и их обсуждение

На основе анализа систематического состава было выявлено следующее: флора железнодорожных путей станции Дема включает 217 видов, относящихся к 144 родам, 37 семействам.

Среднее число видов в семействе равно 5,9. Десять семейств флоры железнодорожных путей содержат количество видов, превышающее среднее число видов в семействе, к ним относятся Asteraceae, Poaceae, Fabaceae, Brassicaceae, Chenopodiaceae, Lamiaceae, Rosaceae, Caryophyllaceae, Polygonaceae, Scrophulariaceae.

Одно семейство флоры железнодорожных путей содержит 5 видов. 2 семейства содержат по 4 вида, 4 - 3 вида, 7 - по 2 вида, 13 - по 1 виду.

Среднее число родов в семействах - 3,9. Среднее число видов в родах $-1,5$. Показатель насыщенности родов невысокий, многовидовых родов немного. Наиболее насыщены видами роды Artemisia (6), Rumex(5), Poa (5), Centaurea (4).

При анализе семейственных и родовых спектров становится очевидным преобладание во флоре станции маловидовых семейств и родов. Так, одно-, двувидовые семейства составляют более половины (54\%) всех семейств флоры, а одно-, двувидовые роды составляют более $58,5 \%$ родов флоры. Подобные соотношения свидетельствуют о значительной роли миграции в процессе флорогенеза [17].

Анализ систематического состава флоры станции Дема показал слабую представленность лилиопсид (28 видов), что подтверждает правило Декандоля о снижении роли однодольных при продвижении с севера на юг, с океанических условий к континентальным. В наших условиях континентальность усиливается еще эдафическими условиями железнодорожных путей. Отношение численности однодольных и двудольных во флоре железнодорожных путей $1: 8$.

К 10 ведущим семействам во флоре станции Дема принадлежат 103 рода $(71,52 \%)$ и 165 видов $(76,03 \%)$. Такое высокое число видов в сравнительно небольшом 131 количестве семейств свойственно территориям с экстремальными условиями развития растительного покрова [17]. В данном случае экстремальные условия формируются воздействием бедности, кислотности и подвижности субстрата.

На железнодорожных насыпях возрастает роль семейств: Brassicaceae, Chenopodiaceae, Polygonaceae, Fabaceae и Lamiaceae. Это очевидно, так как в семействах Brassicaceae, Chenopodiaceae, Polygonaceae много видоврудералов, внедряющихся в хорошо прогреваемые и постоянно нарушающиеся местообитания, а семейства Fabaceae и Lamiaceae являются выходцами из зон с аридным климатом, это указывает на экстремальный и засушливый характер условий, в которых оказались растения, произрастающие на железной дороге.

Во флоре исследуемой территории зарегистрированы новые для Республики Башкортостан виды и местообитания [23] - Ambrosia trifida, Cyclachaena xanthiifolia, Oenothera oakesiana, Oenothera biennis, Phalacroloma strigosum, Senecio viscosus, Eragrostis minor, Eragrostis pilosa.

При анализе происхождения видов большой научный интерес представляет анализ времени заноса синантропных видов, способа иммиграции, степени натурализации. Для выполнения этого анализа были использованы работы В.В. Туганаева, А.Н. Пузырева [19], А.В. Чичева [24] и др.

Результаты анализа показали, что во флоре железнодорожных путей станции Дема преобладают аборигенныевиды, тоестьпредставителиместнойфлоры, включающие 133 вида (61,3\%) (Achillea millefolium, Acinos arvensis, Carum carvi, Dianthus versicolor). Второе место занимают кенофиты (55 видов - 25,3\%), например: Amaranthus albus, Artemisia sieversiana, Berteroa incana, Camelina microcarpa и др. Археофиты представлены 29 видами (13,3\%) (Amaranthus albus, Ambrosia trifida, Atriplex sagittata, Avena fatua и др.). Участие заносных видов во флоре составляет $38,6 \%$, что определяет и степень ее адвентизации.

Основная часть адвентов по способу иммиграции составляет группу ксенофитов (69 видов - 82,1\%), например: Centaurea cyanus, Echium vulgare, Galeopsis ladanum и др. Для них характерен скачкообразный способ заноса и способ распространения сугубо антропохорный. Эргазиофиты объединяют 11 видов $(13,3 \%)-$ Echinocystis lobata, Fraxinus lanceolata, Lycopersicon esculentum и др. Как правило, это пищевые, кормовые, декоративные растения, «убежавшие» из культуры. К аколютофитам следует относить любой вид, появившийся в рассматриваемом районе естественным путем и встречающийся на вторичных местообитаниях. Нами установлено произрастание четырех видов (4,8\%) (Artemisia absinthium, Artemisia austriaca, Chenopodium glaucum, Tragopogon dubius), относимых к аколютофитам.

В составе адвентов железнодорожных путей по степени натурализации преобладают эпекофиты (71 вид - 84,5\%). Например: Ambrosia trifida, Artemisia absinthium, Atriplex patula, Berteroa incana. Во флоре железнодорожных путей присутствует немалое количество агриофитов (7 видов - 9,3\%) (Camelina microcarpa, Carduus thoermeri, Melilotus albus, Melilotus officinalis), успевших войти в состав естественных растительных сообществ. Доля эфемерофитов в составе флоры, составляет 7,1\% (6 видов) (Acer tataricum, Fraxinus lanceolata, Lycopersicon esculentum и др.).

При выявлении флорогенетических центров адвентов с использованием данных В.В. Туганаева, А.П. Пузырева [19], П.В. Куликова [22] мы основывались на систему флористических областей А.Л. Тахтаджяна [25].

Во флорогенетическом спектре адвентивной фракции флоры железнодорожных путей станций преобладают ирано-туранские виды (27 видов - 32,1\% от общего видового состава адвентов), это такие виды, Самарский научный вестник. 2015. № 2(11) 
как Artemisia absinthium, Berteroa incana, Centaurea diffusa и др. Второе место занимают средиземноморские виды (21 вид - 25\%): Bromus squarrosus, Cardaria draba, Echium vulgare, Galeopsis ladanum и др. Высокое участие ирано-туранских и средиземноморских видов объясняется благоприятными условиями для адвентов: высокие температуры летом, сухость и структура почвы, максимум света и т.д.

Третье место занимают североамериканские виды (14 видов- 16,6\%), это такие виды, как Amaranthus albus, Collomia linearis, Hordeum jubatum и др., большое число которых в данной парциальной флоре связано с зональной приуроченностью и интенсивными грузоперевозками.

Таким образом, анализ флоры железнодорожных путей станции Дема показал преобладание апофитов. Адвенты разнообразны по происхождению и натурализации. Однако среди них имеются виды, находящиеся в процессе своего активного расселения, и контроль за ними обязателен. Результаты исследования адвентов железнодорожных путей позволят использовать данные о составе флоры для мониторинга состояния окружающей среды и создать предпосылки для решения экологических проблем.

\section{СПИСОК ЛИТЕРАТУРЫ}

1. Малышев Л.И. Изменения флор земного шара под влиянием антропогенного давления // Научн. Докл. Высшей школы. Биол. науки, 1981. №3. С. 5-20.

2. Скворцова И.В., Березуцкий М.А. Флора железнодорожных насыпей южной части Приволжской возвышенности // Поволжский экологический журнал. 2008. № 1. С. 55-64.

3. Гусев Ю.Д. Расселение растений по железным дорогам Северо-запада европейской России // Бот. журн. 1971. Т. 56, № 3. С. 343-360.

4. Чичев А.В. Адвентивная флора железных дорог Московской области. Автореф. дис. ... канд. биол. наук. М., 1985. 24 c.

5. Пузырев А.Н. О расселении адвентивных растений по железным дорогам Удмуртии // Флористические исследования в Центральной России на рубеже веков. Мат-лы науч. совещ. Рязань, 2001. С.114-116.

6. Борисова М.А. Флора транспортных путей Ярославской области. Автореф. дис. ... канд. биол. наук. Саранск, 2002. 20 с.

7. Григорьевская А.Я., Лепешкина Л.А. Роль транспортных путей в формировании адвентивной флоры г. Воронежа // Вестник ВГУ. Сер. География и геоэкология. 2005. № 1. С. 86-89.

8. Иванова Н.В. К вопросу изучения флоры Куйбышевской железной дороги (в пределах г. Самара) // Самарская Лука: Проблемы региональной и глобальной экологии. 2008. Т. 17. № 3. С. 600-606.
9. Палкина Т.А. О синантропной флоре транспортных путей Рязанской области // Вестник Нижегородского университета им. Н.Г. Лобачевского. 2012. №6(1). C.86- 91.

10. Сенатор С.А., Никитин Н.А., Саксонов С.В., Раков Н.С. Факторы, определяющие формирование флоры железных дорог // Известия Самарского научного центра Российской академии наук. 2012. Т. 14, № 1-1. C.261-266.

11. Третьякова А.С. Роль железнодорожных магистралей в формировании синантропной флоры Среднего Урала // Экология. 2010. № 2. С. 102-107.

12. Хусаинова С.А. Общий анализ флоры железнодорожных путей в пределах г.Стерлитамак // Вестник Оренбургского государственного университета. №16 (135), декабрь 2011. С. 227-229.

13. Абдуллина С.А., Хусаинов А.Ф. Характеристика флоры насыпей железнодорожных путей (Республика Башкортостан станции Алкино, Юматово, Чишмы) // Известия Самарского научного центра РАН. Т. 14, №1 (7), 2012. C. 1672-1675.

14. Башкортостан - краткая энциклопедия. Уфа, 2011. 369 c.

15. Кадильников И.П. Физико-географическое районирование Башкирской АССР/ И.П. Кадильников, А.А. Цветаев, Е.С.Смирнова, М.Ф. Хисматов. Уфа, $2005.212 \mathrm{c}$.

16. Определитель высших растений Башкирской АССР. М.: Наука, 1988, т.1, 316 с. 1989, т.2, 375 с.

17. Толмачев Ф.И. Введение в географию растений. Л.: Изд. Ленингр. гос. ун-та, 1974. 244 с.

18. Ильминских Н.Г. Флорогенез в условиях урбанизиролванной среды: Автореф. дис. ... д-ра биол. наук. СПб: СПбГУ, 1993. 36 с.

19. Туганаев В.В., Пузырев А.Н. Гемерофиты ВятскоКамского междуречья. Свердловск: Изд-во Уральск. Унта. $1988.128 \mathrm{c}$.

20. Черепанов С. К. Сосудистые растения России и сопредельных стран. СПб: Мир и семья, 1995. 992 с.

21. Баранова О.Г., Пузырев А.Н. Конспект флоры Удмуртской Республики (сосудистые растения). М.; Ижевск: Институт компьютерных исследований, 2012. $212 \mathrm{c}$.

22. Куликов П.В. Конспект флоры Челябинской области (сосудистые растения). Екатеринбург, 2005. $537 \mathrm{c}$.

23. Мулдашев А.А., Хусаинова С.А., Хусаинов А.Ф. Новые находки адвентивных растений в Республике Башкортостан // Известия Самарского научного центра Российской академии наук. 2014. Т.16. №1. С. 69-73.

24. Чичев А.В. Синантропная флора города Пущино // Экология малого города. - Пущино, 1981. - С. 18 - 41.

25. Тахтаджян А.Л. Флористические области Земли. Л.: Наука, 1978. 248 с.

\section{ANALYSIS OF ADVENTIVE FLORA STATION DEMA (BASHKIR BRANCH OF THE KUIBYSHEV RAILWAY)}

(C) 2015

S.A. Khusainova, postgraduate student of laboratory «Wild flora and introduction of herbaceous plants» Botanical Garden-Institute USC RAS, Ufa (Russia)

E.S. Seydalieva, student of natural-geographical faculty Bashkir State Pedagogical University. M.Akmullah, Ufa (Russia)

A.F. Khusainov, candidate of biological sciences, associate professor of Bioecology and biological education Bashkir State Pedagogical University. M.Akmullah, Ufa (Russia)

L.M. Abramov, doctor of biological sciences, professor, head of the laboratory «Wild flora and introduction of herbaceous plants»

Botanical Garden-Institute USC RAS, Ufa (Russia)

Abstract. The article discusses the flora railway embankments of the station Dema related to Kuibyshev Railway. Railway embankments are active ways straddling immigrations of alien plant species. On these types of landscapes are formed anthropogenically transformed floristic complexes, in addition involving a large number of adventive species.

Studied in 2013-2014 flora mounds station Dema includes 217 species, of which 84 adventive species. The average number of species in the family is equal to 5.9. Ten leading families flora railways station - Asteraceae, Poaceae, Fabaceae, 
Brassicaceae, Chenopodiaceae, Lamiaceae, Rosaceae, Caryophyllaceae, Polygonaceae, Scrophulariaceae. The largest genera - Artemisia (6 species), Rumex ( 5 species), Poa ( 5 species), Centaurea (4 species).

The time and manner of introduction, the degree of naturalization and florogenetic spectrum of flora were analized. Participation of invasive species in the flora is $38.6 \%$, which determines the degree of its adventization. Among adventive species is high enough role neophytes $(25.3 \%)$. In the flora of the study area for the new account the Bashkortostan Republic species and habitats - Ambrosia trifida, Cyclachaena xanthiifolia, Oenothera oakesiana, Oenothera biennis, Phalacroloma strigosum, Senecio viscosus, Eragrostis minor, Eragrostis pilosa.

Keywords: flora; railways; apophytes; adventive species; synanthropization.

\section{УДК 581.2.07}

\section{СКРИНИНГ ФИТОТОКСИЧЕСКОГО ДЕЙСТВИЯ ПЕСТИЦИДА БИ-58 НА ПРОРОСТКИ} ALLIUM CEPA L. И ZEA MAYS L.

(C) 2015

Д.Э. Эмирова, преподаватель кафедры биологии, экологии и безопасности жизнедеятельности
Крымский инженерно-педагогический университет», Симферополь, Республика Крымм (Россия)

Аннотация. Проведен сравнительный анализ фитотоксического действия пестицида БИ-58 на морфометрические показатели корней семян Zea mays L. и Allium cepa L. Результаты проведенного исследования показали, что БИ-58 в диапазоне изученных концентраций $(0,05-0,4$ мл/л) оказывал негативное влияние на проростки семян Allium сера и Zea mays, проявляющееся в ингибировании корневого прироста и всхожести семян. Данное влияние имело выраженный дозозависимый характер: повышение концентрации тестируемого препарата вызывало снижение изученных показателей у обеих тест-культур. Доза 0,05 мл/л фитотоксического действия на проростки Allium сера и Zea mays не оказывала. Следует отметить, что концентрация БИ-58, рекомендуемая к применению (0,1 мл/л), обладала выраженным фитотоксическим эффектом на тест-растения. Было установлено, что проростки Zеа mays оказались более чувствительными к токсическому действию пестицида, чем Allium сера. На основании этих данных было рекомендовано не использовать данную дозу при возделывании тестируемых культур.

Дальнейшее увеличение концентрации БИ-58 (0,2 и 0,4 мл/л) вызывало сопряженное возрастание фитотоксического эффекта на тестируемые культуры.

При концентрации 0,2 мл/л длина корней Allium сера уменьшилась в 1,5 раза при снижении количества проросших семян на 40,66\%. Увеличение концентрации препарата (0,4 мл/л) вызвало снижение длины корней проростков исследованной тест-культуры и угнетение их всхожести. В частности, длина корней Allium сера в данном варианте исследования снизилась в 1,8 раза по сравнению с контролем, показатель всхожести - на 46,16\%.

Аналогичное влияние пестицид оказывал на Zea mays. В частности, при дозе БИ-58 0,2 мл/л длина корешков Zеа mays снизилась на 45,1\%, показатель всхожести - на 25,3\% по сравнению с контролем. Увеличение концентрации исследуемого препарата в два раза $(0,4$ мл/л) вызвало снижение морфорометрических показателей корешков на $52,1 \%$, снижение всхожести - на 28,8\% по сравнению с контрольным вариантом.

Ключевые слова: пестицид; БИ-58; Zea mays L.; Allium cера L.; семена; корни; фитотоксичность; биоиндикация; фитоиндикация.

Постановка проблемы. В настоящее время общество столкнулосьсрядомэкологическихпроблем,являющихся результатом загрязнения окружающей природной среды. Источниками загрязнения природы вредными веществами являются не только промышленность и транспорт [1-3], но и современное сельскохозяйственное производство с его высоким уровнем химизации $[4,5]$. Недостаточно обоснованное применение новых химических средств, в первую очередь инсектицидов, представленных более опасными, чем фунгициды и гербициды, веществами, привело к ряду случаев гибели водных и наземных животных и загрязнению пищевых продуктов [6]. Данный факт представляет реальную угрозу для здоровья человека, являющегося конечным звеном трофических цепей [7].

Обзор основных исследований по данной проблематике. Сельское хозяйство - важнейшая составная часть хозяйственного комплекса Крыма. Об этом свидетельствует его удельный вес в национальном доходе $-35 \%[8,9]$. Анализ динамики пестицидной нагрузки позволяет прийти к заключению, что за последние годы наметилась тенденция увеличения количества используемых препаратов $[10,11]$, что может привести к загрязнению почв и сельскохозяйственной продукции остаточными количествами пестицидов и их метаболитами [12]. В сельском хозяйстве региона используется много ядохимикатов и удобрений. При невысокой культуре земледелия часть их попадает в подземные и поверхностные воды, загрязняет сельскохозяйственную продукцию, убивает живые организмы, нарушая равновесие в природной среде $[8,9]$. В Крыму довольно широкое применение имеют медный купорос, ГХЦГ, реглон, базагран, фундазол,

каратэ, БИ-58, ДНОК и др. [11, 13].

Непростая экологическая обстановка в Крыму вызвала необходимость расширения масштабов исследований действия техногенных химических загрязнений на высшие растения, используемые в качестве тест-систем [14]. В последние десятилетия для скрининга токсического влияния различных антропогенных поллютантов широко используют методы биоиндикации, так как биологические тесты имеют важное значение в оценке состояния окружающей среды [15]. Данный факт приобретает значимую актуальность в связи с тем, что результаты химического анализа, проводимого с помощью сложного аналитического оборудования, не всегда позволяют оценить истинную опасность разнобразных загрязнителей на среду обитания и прогнозировать последствия их воздействия на биотический компонент экосистем. Известно, что многие загрязняющие вещества, попадая в окружающую среду, могут претерпевать в ней различные превращения, усиливая при этом свое токсическое действие. В связи с этим особую актуальность приобрели биометоды интегральной оценки качества среды (атмосферы, гидросферы, педосферы), в частности, биотестирование и биоиндикации [16]. В силу того, что растения составляют основную массу живого вещества планеты, они широко используются в подобного рода исследованиях (фитоиндикация) [17]. Анализ литературы свидетельствует, что многие исследователи для изучения токсического действия пестицидов используют сельскохозяйственные культуры в качестве тест-объектов. При этом наиболее информативным источником фитотоксического действия исследуемых препаратов является исследование ингибирования их 